\title{
Information and Communication Technologies (ICTS) for Youth Employment in Agribusiness in Ibadan
}

\author{
Stephen Ohuneni ${ }^{1}$, Labode Popoola ${ }^{2}$ \\ ${ }^{1}$ Centre for Sustainable Development (CESDEV), University of Ibadan, Ibadan, Nigeria \\ ${ }^{2}$ Department of Forest Economics \& Centre for Sustainable Development University of Ibadan, Ibadan, Nigeria
}

Email address:

adepamilerin@gmail.com (S. Ohuneni)

\section{To cite this article:}

Stephen Ohuneni, Labode Popoola. Information and Communication Technologies (ICTS) for Youth Employment in Agribusiness in Ibadan. International Journal of Sustainable Development Research. Vol. 5, No. 4, 2019, pp. 91-97. doi: 10.11648/j.ijsdr.20190504.11

Received: June 30, 2019; Accepted: July 24, 2019; Published: December 20, 2019

\begin{abstract}
Information and Communication Technologies (ICTs) remain the viable solution to challenges faced in agriculture and agribusiness through innovations targeted to improve crop yield, value chain processes, and access to market information and creating employment opportunities in the process. In many developing countries especially Sub-Sahara Africa, minimal deployment of ICTs for agricultural production is seen and this has resulted to poor yield, low income for farmers and limited job opportunities. Although, majority of youths see agriculture and agribusiness as a sector not meant for them, this narrative could be changed if their skill and access to ICTs could be harnessed to contribute to the agricultural and agribusiness sector thereby providing real-time employment in the process. This study seeks to identify the levels of ICT skills of youth agripreneurs, investigate the ICT innovations currently being deployed and necessary to improve agribusiness, the extent of youth involvement and investigate dimensions to youth employment in agribusiness. Primary data were collected through an online survey and structured questionnaires. Young people currently involved in agribusiness were interviewed individually to gain insight on the current use of ICT and factors contributing to youth involvement were investigated. Data analysis was done using SPSS to draw inferences and develop policy briefs to provide insights into discoveries of the research and to encourage youth engagement in agribusiness and other rural economic activities. Findings suggest that ICT is currently being deployed for some agribusiness activities but on a very minimal scale. The main conclusion of the study is that in order to increase food security and provide job opportunities for young people, an increase in the uptake and deployment of ICT innovations for agribusiness needs to be encouraged.
\end{abstract}

Keywords: Information and Communication Technologies, Youth Employment, Agribusiness, ICT Innovations, Value Chain Processes

\section{Introduction}

Agriculture in Africa has been primarily practiced traditionally by smallholders and pastoralists with minimal mechanization and technology use. This form of agricultural practice has led to various challenges and is limiting the transformation of the agriculture sector. Also, the lack of transforming farm produce to value-added products through value chain processes and agribusiness has limited the income of farmers and has subjected them to inconsistent profits and persistent poverty. Furthermore, the decreased involvement of youth in agriculture with the clamor for white collar jobs which are unavailable has increased the burden of unemployment and left many in poverty.
Therefore, something different has to be done if these issues are to have a paradigm shift. Information and Communication Technologies (ICTs) seem to have creative solutions to address some of these challenges. ICTs could improve crop yield and productivity, provide credible information on climate conditions, engage young people productively and improve agribusiness value chain processes. Against this backdrop, this study examines the ICT innovations capable of promoting agribusiness and youth employment in Nigeria. This study is designed to investigate the ICT innovations useful in transforming the agricultural sector with significant focus on agribusiness and that could provide employment for the youths. 


\subsection{Review of Literature}

According to Sanginga (2015), Africa having youngest population in the world, has each year 10-12 million of its young people seeking to enter the continent's workforce, but too many without success. This great challenge of youth unemployment can also be seen as an opportunity for them to become the engine driving new agriculture and agribusiness enterprises as well as rural transformation [13]. The Technical Centre for Agricultural and Rural Cooperation ACP-EU (CTA) (2016) also noted that while the need for creative solutions to raise agricultural productivity and the huge prospective market for their ICT-enabled services in agriculture have been recognized by young innovators in Africa, the Caribbean, and Pacific region, they still face many challenges, although their products have the potential to transform agricultural value chains in developing countries [15].

Stamm et al., (2006) argue that a developmental path focusing on agribusiness is at least one promising option of achieving a socially inclusive growth under the conditions of globalization. Agriculture represents important, absolute and comparative advantages for many developing countries. A growing and increasingly differentiated demand open opportunities to place a variety of goods on local, regional, and global markets. A generation of new sources of income in agribusiness is an especially valuable option to meet the challenges of development cooperation. According to Okediji (2015), the use of ICTs to provide solutions to problems in the agricultural sector is referred to as ICT for Agriculture (ICT4Ag). E-agriculture is currently attracting youths to agriculture and some have started identifying opportunities for income generation through enterprises that deliver ICT empowered services both to farmers and also to other actors in agriculture. The advent of ICT in the agricultural sector is now forming part of what is attracting young people into the sector and is changing the face of Africa's agriculture.

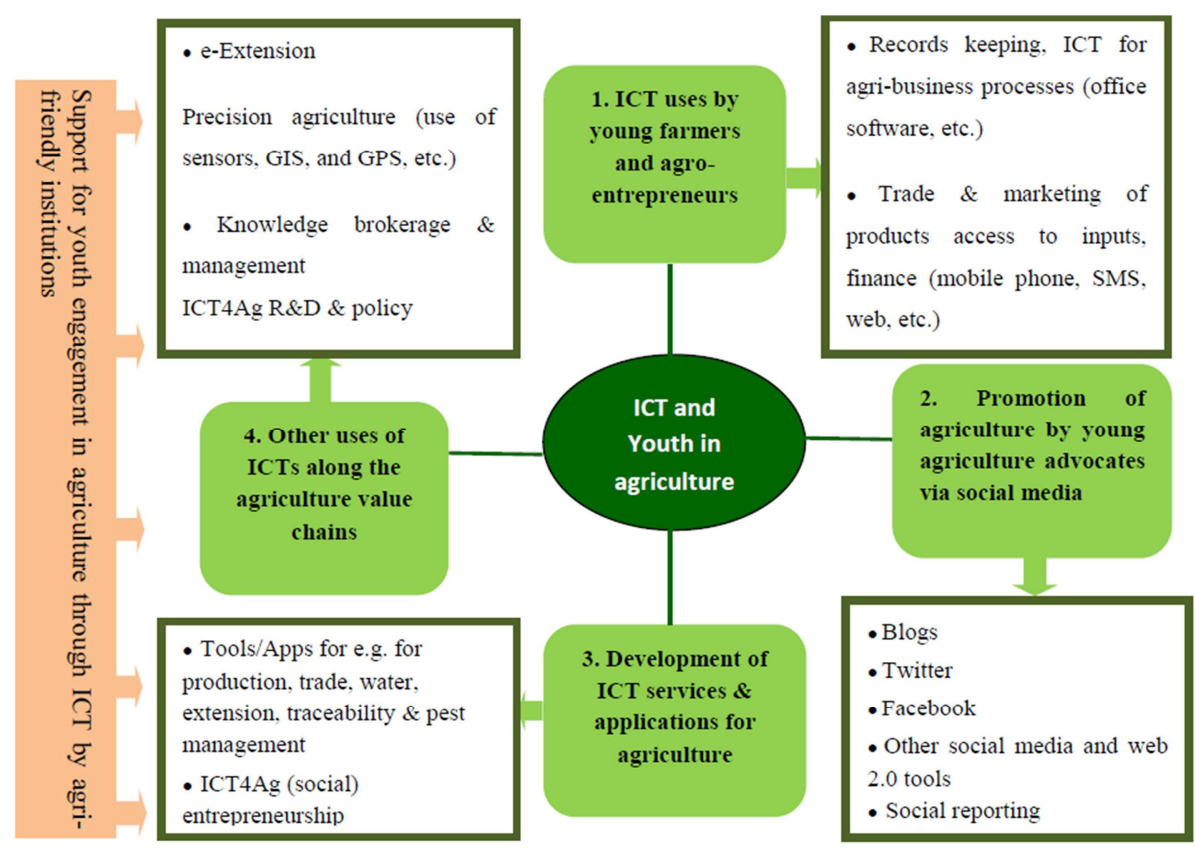

Source: The CTA ARDYIS (Agriculture, Rural Development and Youth in the Information society) project framework is adopted for this study.

Figure 1. Theoretical Framework for engaging youth in agriculture through ICTs.

Agriculture remains a viable means of getting many young people engaged economically. Nonetheless, over the past few decades, a large percentage of youth have abandoned agriculture and farming because of its low productivity, its persistent negative image, the unappealing characteristics of rural areas, and other challenges in Africa [10]. ICT applications in agriculture are giving rise to a new generation of tech-savvy young African agripreneurs who now see farming as a business venture (rather than a way of life) and have the ability to learn improved practices with just a click [1]. In general, there is a limited understanding of the relevance and benefits of ICT applications for increasing the productivity and profitability of many stakeholders in the sector. This adversely affects ICT investment in agricultural education, in agricultural institutions and in the sector as a whole. Some successful agripreneurs, do not see a reason to use or invest in ICTs, because they do not understand the additional benefit that they can bring to their activities [7]. ICTs have the potential to increase farm productivity by supporting the efficient use of key resources like water, fertilizer, and land [3]. Farmers can now use IT tools to manage their farming activities, from crop selection to the monitoring of production [16].

Geographic information systems (GIS) enable the capture, analysis, management, and display of geographical and spatial information [9]. They can include the use of GPS (Global Positioning System) receivers, which connect to satellites to facilitate access to locations. The GPS has been notably beneficial to agriculture in monitoring climate variability, and for providing current weather forecast for 
early warning systems that guide decision-making by farmers and relevant government agencies [12]. Researchers realized that gender, marital status, educational level, and land ownership, influence the purpose for which young farmers adopt ICT tools, as well as the extent of adoption. Because of limited access to land in many African communities, young women in rural areas often do not feel they have strong enough incentive to learn to apply ICT tools in their farming activities. Also because of their busy schedules and domestic routines, married women have limited time available to use community ICT centers $[6,17,2]$.

IICD (2013) concluded that equipping the farmers of tomorrow with the right tools is crucial to ensure the future viability of the agricultural sector, tackle rural poverty and also create employment opportunities [5]. When an integrated approach to ICTs and capacity development is put in place it amplifies efforts in the agricultural sector to boost economic development and increase youth participation". GIZ projects (2014) also discovered that "an increasing number in the developing world also in rural areas now have access to new and modern information and communication technologies (ICT) like mobile banking, weather forecasts and market prices". Poor agricultural practices, yields, and revenues are transformed in a large number of developing countries into farming to economically sustain and improve the livelihoods of hundreds of millions of small farmers, and continue to feed the world's growing population as ICT4Ag is increasingly being considered as a potentially powerful entry point and instrument [4].

\subsection{Problem Statement}

In many African countries, agriculture and agribusiness could land the kind of economic transformation seen in many emerging economies in other regions such as Thailand, Indonesia, Brazil, Columbia and Ukraine. Agriculture in Africa could be transformed by bringing the business perspective to it and creating value throughout the process from inputs, production, industries to the end user which is called agribusiness. In recent times, findings show that 7.9 million Nigerian youth aged 15-34 are currently unemployed and about $58.1 \%$ of youth within this age bracket who are currently working, are underemployed [11]. All stakeholders were urged to take necessary actions to end hunger (Goal 1), double agricultural productivity of small-scale food producers by 2030 (Goal 2, Target 2.3), and promote policies that support entrepreneurship (Goal 8, Target 8.3) as part of the Sustainable Development Goals (SDGs) that the United Nations adopted in September 2015. Nonetheless, agriculture is facing new and severe challenges in its own right; underinvestment in rural areas, inadequate access to markets and unfair market conditions, inadequate access to technologies, weak infrastructure, high production, and transport costs, conflicts, natural disasters, deforestation and environmental degradation. African agriculture is mainly traditional and practiced by smallholders and pastoralists which is predominantly rain-fed, has low-yielding production, and lacks access to critical information.
Consequently, these have led to underdevelopment in rural areas, poverty, and low incomes, inequality in technology access, dilapidated infrastructure, climate-threatened production and unprofitable agricultural economic activities and endeavors. These challenges and their effects are frequently faced by smallholder farmers and rural agripreneurs in Africa including Nigeria which if not addressed could threaten the movement of rural population out of poverty and make sustainable development unachievable. Conversely, increasing the productivity and sustainability of agriculture depends, to a large extent on engaging young people in the sector, drawing on their energy and innovations. The role that ICTs can play in addressing these challenges is increasing as technological innovations are being developed and access to these technologies is becoming widely available through personal ICT devices such as mobile phones or tablet PCs. The ICTs, when integrated into broader stakeholder systems can bring economic development and growth as it can help bridge critical knowledge gaps and increase yield among smallholder farmers, youth agripreneurs, and rural population. Agribusiness can be greatly promoted through ICT innovations from youths contributing through skills access which would in the process create job opportunities and employment. A large population of unemployed youth can be drawn to agribusiness through ICT leading to incremental growth in the agribusiness and agricultural sector and tackle unemployment also.

\subsection{Objectives of the Study}

The overall objective of the study is to assess information and communication technologies for youth employment in agribusiness. The specific objectives of the study include the following:

i. To determine the levels of ICT skills among youth agripreneurs.

ii. To assess the ICT innovations necessary to improve agribusiness.

iii. To investigate if employment opportunities could be provided in agribusiness through ICT.

\section{Methodology}

Purposive sampling method was adopted for this study since the target populations are youths including those involved in agribusiness and other occupation and are age defined. The respondents comprised of significant youths between the ages of 18 and 35 ranging from employed, agripreneurs, students and unemployed. The distribution was carried out such that the representation of respondents was without bias. A total of 101 respondents were used for this study. Two forms of data collection methods were used; the administration of structured questionnaires and an online survey. The structured questionnaires were administered to mainly youth agripreneurs in IITA Ibadan at a conference organized by the IITA Youth Agripreneur program, while the online survey was accessed by various categories of youth 
including agripreneurs, students and unemployed.

The respondents were encouraged and assured of their privacy as there was no traceable personal information that may implicate them or expose them to any danger. The questionnaires were administered to the sample selected for the study by the researcher who was available to render any guidance to the respondents as the participant in the study. To ensure the validity of the instrument for data collection, it was subjected to face and content validity with the assistance of experts in research study and statistics specialists. The validation aided in ensuring that all objectives were covered at the same time capturing the content of what was being assessed in the research. A pre-test was carried out to determine the instrument's reliability prior to the commencement of data collection. The pre-test was conducted with 5 young agripreneurs selected from the study area in Ibadan in order to ensure that necessary modifications are made before the final administration.

\section{Results}

\subsection{Socio-demographic Characteristics of Respondents}

The results of this study reveal that of the 101 respondents interviewed, $73.3 \%$ were male while $26.7 \%$ were female. The age categorization data shows that the youth population aged between $(21-25,26-30$ and $31-35)$ were $(12.9 \%, 64.3 \%$ and $8.9 \%$ ) respectively totaling $86.1 \%$ of the entire age groups. The results further shows that the respondents are mostly farmers/agripreneurs $(67.3 \%)$, followed keenly by students $(15.8 \%)$, the remaining occupations were civil servants with $5.9 \%$, unemployed with $2.0 \%$ while other unidentified occupation had $5.0 \%$.

Table 1. Demographic Composition of Respondents.

\begin{tabular}{lll}
\hline Domain & Frequency & Percent \\
\hline Gender & 74 & 73.3 \\
Male & 27 & 26.7 \\
Female & 101 & 100.0 \\
Total & & \\
Age Group & 13 & 12.9 \\
$21-25$ & 65 & 64.3 \\
$26-30$ & 9 & 8.9 \\
$31-35$ & 13 & 12.9 \\
$36-40$ & 1 & 1.0 \\
$>40$ & 101 & 100.0 \\
Total & & \\
Occupation & 68 & 67.3 \\
Agripreneur/farmer & 4 & 4.0 \\
Businessman & 6 & 5.9 \\
Civil servant & 16 & 15.8 \\
Student & 2 & 2.0 \\
Unemployed & 4 & 5.0 \\
Others & 100 & 100.0 \\
Total & &
\end{tabular}

Source: Field Survey, 2018.
Table 2. Level of ICT Skills of Respondents.

\begin{tabular}{lll}
\hline Domain & Frequency & Percent \\
\hline Level of ICT Skills & & \\
Beginner & 7 & $7.0 \%$ \\
Intermediate & 46 & $46.0 \%$ \\
Advanced & 39 & $39.0 \%$ \\
Expert & 8 & $8.0 \%$ \\
Total & 100 & 100.0 \\
\hline
\end{tabular}

Source: Field Survey, 2018.

Table 3. ICT Innovations aiding agribusiness activities.

\begin{tabular}{lll}
\hline Domain & Frequency & Percent \\
\hline ICT Innovations & 46 & 46.0 \\
Market Information System & 8 & 8.0 \\
Geographic Information System & 4 & 4.0 \\
Geographic Positioning System & 1 & 1.0 \\
E-Pest Management & 1 & 1.0 \\
Yield Monitoring & 1 & 1.0 \\
Field Monitoring & 1 & 1.0 \\
Soil Sampling & 1 & 1.0 \\
Twitter & 4 & 4.0 \\
Facebook & 29 & 29.0 \\
Others & 4 & 4.0 \\
Total & 100 & 100.0 \\
\hline
\end{tabular}

Source: Field Survey, 2018.

Table 4. Employment Opportunities through ICT.

\begin{tabular}{lll}
\hline Domain & Frequency & Percent \\
\hline ICT Employment Opportunities & & \\
Yes & 95 & $95.0 \%$ \\
No & 5 & $5.0 \%$ \\
Total & 100 & 100.0 \\
\hline
\end{tabular}

Source: Field Survey, 2018.

\subsection{Levels of ICT Skills among Youth Agripreneurs}

The study examined the level of ICT skill among youth agripreneurs, while $7 \%$ said they are at beginner level, $46 \%$ indicated that they had intermediate level of skills, $39 \%$ indicated that they are at advanced level and only $8 \%$ were at expert level of skills.

\subsection{ICT Innovations Available and Applicable in Improving Agribusiness}

This study investigates the ICT innovations that has aided and improved agribusiness activities. The results show that Market Information System (MIS) has aided the agribusiness activities of most respondents as $46 \%$ of the respondents indicated this while Facebook the next to it which $29 \%$ of the respondents said has aided their agribusiness activities and has resulted to improved income, others are; Geographic Information System (4\%), Geographic Positioning System (1\%), E-Pest Management (1\%), Yield Monitoring (1\%), Field Monitoring (1\%), Soil Sampling (1\%), Twitter (4\%), and Others (4\%). 


\subsection{Employment Opportunities in Agribusiness through ICT}

Respondents were asked if they thought ICT could provide employment opportunities for youths in Agribusiness and results shows that $95 \%$ indicated in the affirmative while only $5 \%$ stated otherwise.

Table 5. Chi-Square test for difference between level of ICT knowledge and contribution of ICT to income.

\begin{tabular}{lllll}
\hline & Value & df & Asymp. Sig. & Remark \\
\hline Pearson Chi-square & $2.816^{\text {a }}$ & 3 & 0.421 & Not Significant \\
No of valid cases & 96 & & & \\
\hline
\end{tabular}

Source: Field Survey, 2018.

There is no significant difference between ICT innovation used and rating of contribution to agribusiness activities, at $95 \%$ confidence interval as the asymptotic significance is above $0.05(0.421)$.

Table 6. Chi-Square test for significant difference between gender and employment opportunities for youth in agribusiness through ICT.

\begin{tabular}{lllll}
\hline & Value & df & Asymp. Sig. & Remark \\
\hline Pearson Chi-square & $0.122^{\mathrm{a}}$ & 1 & 0.727 \\
No of valid cases & 101 & & Not Significant \\
\hline
\end{tabular}

Source: Field Survey, 2018.

There is no significant difference between gender and employment opportunities for youth in agribusiness, at 95\% confidence interval the asymptotic significance is above 0.05 (0.727).

\section{Discussion}

The motivation for this study arose from the need to understand how ICT could provide employment for youth in agribusiness. The study examined the levels of ICT skills among respondents which is crucial if ICT is to transform into employment in agribusiness. It was found out that $46 \%$ were at intermediate skill level, 39\% were at advanced skill level, $8 \%$ were at expert level while only $7 \%$ were at beginner level. This shows that most of the respondents have above beginner ICT skill level and could transform this skill into employment in agribusiness.

Also investigated was the specific ICT innovations that has aided agribusiness activities. From the results it was revealed that Market Information System has the greatest influence on respondents' agribusiness activities with $46 \%$ and keenly followed by Facebook with $29 \%$, other innovations only have very minimal influence on the respondents' agribusiness activities. The respondents were also asked if they feel ICT can provide employment for youth in agribusiness and majority (95\%) answered in the affirmative while only $5 \%$ stated otherwise. These results shows that ICT has the capacity to provide employment for youth in agribusiness especially in Nigeria where opportunities abound with large market share size and available innovations that could be improved upon.

Hypotheses were tested to find out the difference between ICT knowledge and contribution to agribusiness activities. It was observed that at $95 \%$ confidence interval, there is no significant difference between ICT knowledge and contribution to agribusiness activities. Also tested was the difference between gender and employment opportunities in agribusiness at $95 \%$ confidence interval. Result show that there is no significant difference between gender and employment opportunities in agribusiness.

\section{Recommendations and Conclusion}

\subsection{Conclusion}

Findings from the study identified ICT as a tool for youth employment in agribusiness. ICT remains a viable and effective solution for youth employment in agribusiness which if harnessed could take the majority of the youths off the street into productive engagement and income while also contributing to the economy. ICT innovations currently being used in this sector need to be improved upon and new innovative solutions coming to space which through the creativity of the youth the sky is the starting point. The importance of ICT knowledge among agripreneurs to enhance income through effective deployment of ICT for agribusiness activities cannot be overemphasized. Knowledge of ICT and access remain key components in the productive deployment of ICT to bring about an increase in productivity and profit (income) in agribusiness. Without relevant ICT knowledge and access to effectively deploy these ICT innovations, positive results would not be achieved.

Furthermore, market information system and Facebook remain the mostly used ICT innovation currently in agribusiness as established in this study which is also in alignment with the study done by [8], who said "ICTs are also used to find the best locations and prices of such inputs as seed and fertilizers" and it gives an opportunity for a variety of new innovative solutions targeting other areas of agribusiness value chain processes. Other innovations that are currently being used could be improved upon by the creative youthful population making the solutions userfriendly and need-based. Opportunities exist for young ICT specialists in agriculture to develop innovative and useful 
ICT solutions for African agriculture which could provide massive employment opportunities for youth in agribusiness. Concerted effort by the government and various organizations in the sector should be made in making these opportunities available and accessible to the youth both rural and urban, both genders.

\subsection{Recommendations}

Based on the findings of this study, the following are recommended:

Since ICT skill and knowledge is crucial for ICT deployment for agribusiness activities, the government should develop continuous digital literacy programs for young farmers and agripreneurs that would train youth to understand and use relevant ICT devices and applications. Limited ICT innovations are currently being used which opens up opportunities for more creative innovative solutions Therefore, government and private organizations should invest in training of the youths and significant empowerment to create innovative solutions needed in the agriculture sector, most especially youths that are ICT specialist and have interest in agriculture.

The level of youth involvement in agribusiness is quite low. Therefore, policies should be formulated to encourage more youth participation and involvement in agribusiness through proper incentives, grants and enabling environments. Government and the various organizations supporting the sector should put in place favorable and dedicated financial schemes for young farmers and agripreneurs who are seeking (micro) credit to invest in ICTs that will help them develop their activities and businesses.

Strengthen ICT incorporation into agricultural curricula: Governments and policymakers should encourage or mandate the expansion and reinforcement of ICT training into the agricultural curricula, particularly at University level. This is essential for grooming a generation of young agriculturalists prepared to take full advantage of ICT innovations in their professional work immediately following graduation. Support ICT for agricultural research, innovation and youth entrepreneurship: youth innovations (software and hardware) are advancing agricultural value chains, and at the same time providing employment opportunities and attracting more youth to agriculture - in a large part by improving its image. Financial support should be readily available (via innovation funds, seed funds, venture capital organizations, and other financial mechanisms) to support the emergence of prototypes, the development of proofs of concept, and the scaling up of entrepreneurial innovations. Multi-stakeholder support in this area is crucial to sustaining successful ICT4Ag business models and (social0 entrepreneurship in Africa.

The NGOs, CBOs, FBOs and other organizations working in the field of agriculture and agribusiness should engage in partnerships to roll out support and awareness to engage youth massively in agriculture through programmes, projects, and events targeted at encouraging the youth to engage in agriculture and agribusiness. The civil organizations should create a network that consciously educates and sensitize the youth on the opportunities that lie in agriculture and agribusiness especially through ICT.

\section{Acknowledgements}

Our deep appreciation goes to the Lord Almighty, for giving us the opportunity and grace to embark on and accomplish the task of writing this project, we could not have achieved this without him. Our appreciation also goes to the Director, Centre for Sustainable Development (CESDEV), Prof. Olanrewaju Olaniyan, Course Coordinator; Dr. Olawale Olayide, entire staff of CESDEV and to people like Bukola Adewumi. We offer our candid appreciation for the learning opportunities provided by Centre for Sustainable Development, University of Ibadan. Thank you all.

\section{References}

[1] Ajilore, O. (2014). Creating an Upward Spiral. ICT Update 78 , Young Voices Column. http://ictupdate.cta.int/Regulars/Youngvoices/Creatinganupwa rdspiral/78/1409248150.

[2] CTA and AYF (2015). Youth sustaining family farming through ICTs: Report of e-Debate Organised by the Technical Centre for Agricultural and Rural Cooperation ACP-EU (CTA), incollaboration with the African Youth Foundation (AYF), in the framework of the International Year of Family Farming (IYFF) 2014.

[3] Deloitte. (2012). eTransform Africa: Agriculture Sector Study: Sector Assessment and opportunities for ICT.

[4] GIZ (2014). "Use of ICT for Agriculture in GIZ projects Status quo, opportunities and challenges". Sector Network Rural Development Africa (SNRD).

[5] IICD. (2013). Youth, ICTs and Agriculture: Exploring how digital tools and skills influence the motivation of young farmers. International Institute for Communication and Development Publication November 2013. http://www.iicd.org/about/publications/ict4d-effects-youthicts-and-agriculture.

[6] Kimani, M. (2012). Women struggle to secure land rights: Hard fight for access and decision making power. Africa Renewal Magazine Special Edition on Women. 2012. Pg. 37.

[7] Kimbowa, J. (2013). Blending agriculture and mobile phones. The Observer (Uganda). http://www.observer.ug/index.php?option=comcontent\&view $=$ article $\& \mathrm{id}=28682$ : blending-agriculture-andmobilephones\&catid $=79$ : businesstopstories $\&$ Itemid $=68$.

[8] Lohento, K. and Ajilore, O. D. (2015). ICT and Youth in Agriculture. Africa Agriculture Status Report, 2015. Chapter 5; p119-142.

https://www.researchgate.net/publication/308968253.

[9] Maliene V, Grigonis V, Palevi - ius V, Griffiths S. (2011). "Geographic information system: Old principles with new capabilities". Urban Design International 16 (1). pp. 1-6. doi: 10.1057/udi.2010.25. 
[10] Montpellier Report (2014). Small and growing entrepreneurship in African agriculture. Agriculture for Impact/Montpellier Panel Report June 2014.

[11] National Bureau of Statistics (2012). "Demographic distribution of Nigeria: By sector, geopolitical zone and climate". NBS publication vol. 212. Pp 86.

[12] Pearson, L. (2012). Early warning of disasters: Facts and figures. SciDev Net. http://www.scidev.net/global/communication/feature/earlywarning-of-disasters-facts-and-figures-1.html.

[13] Saginga, N. (2015). Youth in Agribusiness within an African Agricultural Transformation Agenda.
[14] Stamm, A, Jost, C, Kreiss, C, Meier, K, Pfister, M, Schukat, P and Speck, H. A. (2006). "Strengthening Value Chains in Sri Lanka's Agribusiness". German Development Institute.

[15] Technical Centre for Agricultural and Rural Cooperation ACP-EU (CTA) (2016). "Youth e-agriculture entrepreneurship". ICT Update bi-monthly Magazine Issue 83.

[16] World Bank (2011). "ICT in Agriculture: Connecting Smallholder Farmers to Knowledge, Networks and Institution”. E-Source book Report Number 6460.

[17] Yeboah, E. (2014). Women's land rights and Africa's development conundrum - which way forward? IIED Blog. http://www.iied.org/womens-land-rights-africas-developmentconundrum-which-way-forward. 